\title{
MATURE-AGED WORKERS’ LEARNING NEEDS AND MOTIVATIONS FOR PARTICIPATION IN TRAINING PROGRAMS
}

\begin{abstract}
Issues arising from an ageing society, a low fertility rate and growing need for a skilled work force, have seen increased government commitment to improving the participation rate of mature-aged workers. Education and training are seen as a principal strategy to increase the employability of these workers, yet participation in training is low and declines with age. Based on a study of 8 mature-aged participants enrolled in an accredited training program, this paper identifies their learning needs and motivations. The findings identify a range of institutional and personal factors that shaped their participation. Given the diversity of personal factors identified within this small sample, it is unlikely that creating one policy or training approach would address the education and training needs of this cohort. Hence, there is a need to understand more fully how the diverse needs of mature-aged workers can be accommodated within the vocational education and training system.
\end{abstract}

\section{KEY WORDS}

Mature-aged workers, employability, training programs, institutional factors, personal factors, vocational education and training 


\section{MATURE-AGED WORKERS NEED TO REMAIN EMPLOYABLE}

In the last decade, like in many other countries with advanced industrial economies, the Australian government has demonstrated interest in increasing the participation rate of mature-aged workers in the national workforce to respond to a range of social and economic issues arising from the changing national demographics (Australian Bureau of Statistics [ABS], 2009). In particular, the ageing population and low fertility rate are seen as increasingly hindering the nation's capacity to achieve economic and social goals that are central to existing levels of productivity and quality of life (Kossen, 2004; McFarlane, 2004). Education and training have become the principal strategy to increase the employability of this cohort of workers (Barton, 2005). However, while workers of this age group holding tertiary qualification are more likely to remain employable, the participation by mature-aged workers in accredited training programs is low (Department of Employment, Education and Workplace Relations [DEEWR], 2008) and continues to decline with age (Australian Human Rights Commission, 2009). Hence, there is an imperative to increase the participation of mature-aged workers in structured and certified vocational education programs to assist in securing their employability. This article identifies and discusses factors, both institutional and personal, that inform how mature-aged workers' (i.e. those aged between 45 and 64 years) (Dawe, 2009) elect to participate in such training programs and, as a result, how their participation in training programs might be best organised through understanding and meeting their needs as lifelong learners. This is an important issue, because the Australian population is ageing at an unprecedented rate, faster than the birth rate can match (The Treasury, 2004). Indeed, soon workers aged over 45 will comprise the largest proportion of the Australian work-force (ABS, 2009) and increasingly, they are expected to stay employed and workplace competent longer than in the past, in order to play an increasingly central role in realising the nation's economic and social goals (ABS, 2009). For instance, the recent increase in the age for pension-entitlements to 67 years underlines this imperative and trend for working lives 
that not only need to be longer, but requires workers to remain employable (i.e. productive and able to respond to new challenges) later into their lives than previous generations. Therefore, there are growing governmental and societal imperatives to assist these workers to continue to engage effectively in productive work activities across longer working lives. An important means for supporting their employability and ensuring mature-aged workers remain current and competent in their work is for them to have access to and engaging in structured and certified vocational education and training, as these are aligned with continuing employability (Karmel \& Nguyen, 2007). Contrary to this intention, however, these workers’ engagement in education and training decreases with age (ABS, 2009). Therefore, to reverse this trend and promote mature-aged workers' participation in training programs, it is necessary to identify factors shaping their engagement and success in such programs and use these factors to inform policy about how vocational education provisions might best be organised.

Based on the findings from an exploratory study of 8 participants in an accredited training program, the learning needs and motivations of mature-aged workers generally are discussed with reference to increasing their participation in these kinds of programs. The findings identify a range of key personal and institutional factors that have shaped decisionmaking about participating in such programs. Institutional factors, (i.e. those that are a product of society (Searle, 1995) such as ageism and inequitable workplace affordances are widespread and exist despite legislation and government funding to suppress them (Billett \& van Woerkom, 2008). Personal factors, (i.e. those that are a product of personal intentionality, interest and preference) as expressed through their individual epistemologies or ways of understanding, knowing and doing (Billett \& van Woerkom, 2008), ontogeny or life history (Billett, 1998) and agency or active engagement (Billett \& Pavlova, 2005) are also salient. Moreover, not only are these factors person-particular but they are central to how individuals 
negotiate with what they are afforded by societal or institutional factors. However, given the diversity of personal factors, it is unlikely that creating one policy or training program would address all of their needs. Instead, it is proposed that if the national goals of increasing participation in these programs are to be advanced, these workers' needs require to be more comprehensively understood, and to be addressed in curriculum measures and program provision that both meet their needs and invite their participation. These goals may be possible with significant input from mature-aged workers themselves, specifically through means that allow them to describe their own experiences and identify something of the differences in their readiness to participate.

In all, it is proposed that while governmental goals are important and understandable, even for these to be realised it is also necessary to account for the range of personal factors that both direct and mediate these workers' participation in training programs. This suggests that, rather than structural factors such as supply and demand, a range of personal factors will shape mature-aged workers' efforts and actions to remain employable. In making its case, the paper is structured as follows. Firstly, a review of literature identifies three themes that explain the recent focus on the importance of mature-aged workers remaining employable and the need for greater participation by this cohort in training programs. These themes comprise: i) the identification of current and dynamic demographic trends and a range of ii) institutional and iii) personal factors impacting on mature-aged workers’ participation in such programs. Secondly, the context and significance of the study investigating these factors are outlined and the study's methodology and procedures are explained and justified. The findings of the study are then elaborated and five discrete, but interlinked themes that emerge from the analysis are advanced and discussed. Finally, implications are drawn from the findings that suggest that both institutional and personal factors influence mature-aged workers' participation in training programs and it is negotiations between these two factors which shapes participation 
in structured and certified training programs.

\section{TRENDS NECESSITATING PARTICIPATION IN TRAINING PROGRAMS}

A review of relevant literature identifies three key areas that assist in explaining the need to motivate and engage mature-aged workers to participate in training programs, and why this participation still remains relatively low, despite interest and action by peak government and industry bodies. The first theme is the current Australian demographic trends, which, together with those of other Organisation for Community and Economic Development (OECD) countries, highlight the shifts in the age profile of the workforce (Australian Human Rights Commission, 2009). The percentage of the labour force in the 45-64 age group during the period between 2000 to 2012 is projected to rise to 85\% of the Australian working population (Rolland, 2004). Yet the labour force participation rate is declining with age, especially after age 55 (Hancock, 2006). The consequences of a continuation of the current Australian demographic trends are reported to be already negatively affecting the national labour market and economy (Productivity Commission, 2005). This trend highlights the need to increase the labour force participation rate of mature-aged workers (Dimopolous, 2005), without whose contribution there may be a severe decline in the nation's capacity to realise important economic and social goals (Kossen, 2004; McFarlane, 2004). This need for increased worker participation is the second theme that helps to explain the necessity to sustain and extend the working lives of people aged over 45. Typically, the response to this need is to consider how best to 'up-skill' (Barton, 2005) or to engage mature-aged workers in the ongoing development of their workplace competence. However, realising this goal is negatively affected by an array of both personal and institutional or societal factors, which impact on the ability of mature-aged workers to engage in either the labour force or in training programs. The third theme comprises the range of societal factors that mediate these workers effective participation in work and further education opportunities, foremost of which appears to be a 
widespread discrimination against mature-aged workers (Encel, 2003; Kossen, 2004), primarily from employers (Dimopolous, 2005; Hancock, 2006). Consistently, the literature reports that mature-aged workers are being excluded from participating further in training programs due to both non-inclusive, discriminatory employer attitudes and policies in their workplaces (Billett \& van Woerkom, 2008), and a lack of training programs targeted to their needs (DEST, 2005).

Thus, there is a discrepancy between the need to increase the labour force participation rate of mature-aged workers through training strategies and initiatives, and the data, primarily from figures provided by the National Centre for Vocational Education Research (NCVER), that identify a lack of significant numbers of mature-aged workers participating in such training. What these data highlight is how sets of factors beyond the individual, and which are institutional in origin, shape the bases for, means by which and prospects arising from matureaged workers' participation in continuing education. For instance, in the 'Australian Industry Report 2006', although 79\% of employers surveyed stated the importance of up-skilling existing and mature-aged staff, several barriers were identified such as: i) insufficient financial incentives from the government, ii) training cannot be accommodated around work demands and iii) lack of workers to act as trainers. The report concluded these barriers could prevent employers successfully implementing supportive training practices for mature-aged workers and it was suggested that appropriate government policy formation and financial incentives to employers could encourage employers to support the training of mature-aged workers (Spindler, 2006). To address this need, there are several organisations and government bodies that are dedicated to the training and employment of this age cohort, such as the Council of the Ageing (COTA), the website "jobWise” (Department of Education, Employment and Workplace Relations [DEEWR], 2008) and the website “OlderWorkers.com.au” (Older and Mature Age Workers, 2007). It has been suggested that 
the focus on training for these workers be re-directed, with regard to a broader policy formation (Smith \& Billett, 2005; Hancock, 2006), to address disparities between government policy and practice. These disparities relate largely to the current Australian retirement arrangements and the disability support pension, which may be providing greater disincentives for mature-aged workers to participate in the labour force (O’Connell, 2005: Linacre, 2007). However, Western European countries are overhauling their social security system in response to the current dynamic economic situation. In the Netherlands, for instance, recent government measures regarding benefits have been directed at increasing the vested interest of all parties: employers and employer organisations, employees and the trade unions, benefits claimants and implementing bodies. There are financial incentives and disincentives for employers, employees and implementing bodies that place their responsibility and obligations in order to encourage participation in the workforce, rather than encourage reliance on the social security benefits. The system includes privatisation of the sickness scheme and is now designed to protect income yet foster re-activation in employment. These changes are aimed at ensuring those who are low-skilled, disabled and ageing, are integrated into the society and thus employment. In the light of the current ageing population debate, the Australian retirement arrangements and disability support schemes could take some tips from the system in the Netherlands (Organisation for Economic and Community Development [OECD], 2010).

However, the base of investigations that explore and elaborate both the specific and the more general issues remains quite limited and lacks adequacy in explaining these factors and advising how best they might be addressed. A particular gap in the available literature is a shortage of qualitative accounts of what factors direct and motivate mature-aged workers' participation in training programs. In particular, there is a shortage of these accounts that engage mature-aged workers in providing their perspectives. Despite these concerns being a 
focus of attention in national and international government organisations such as the OECD and industry groups, the opinions of these workers have not been fully explored. Hence, an initial and small scale investigation was conducted to gauge these issues, which are now discussed here.

\section{MATURE-AGED WORKERS' PARTICIPATION IN CONTINUING TERTIARY EDUCATION}

Mature-aged workers' participation in training programs is likely influenced by external factors, such as regulatory requirements of their industry or enterprises. These institutional factors are mandated by industry; however, participation by mature-aged workers in such training programs is also predicated on workplace affordances, that are impacted by more subtle, but widespread external factors, that of workplace practices and policies. Indeed, certain workplace practices and policies may hide a culture of age discrimination (Australian Human Rights Commission, 2009). For instance, there may be inequitable distributions of workplace learning opportunities granted to mature-aged workers, influenced neither by legislation nor government funding (Billett \& van Woerkom, 2008). Understanding these factors, which can be referred to as institutional because they are societal (Searle, 1995), and their impacts, may assist and inform the process of constructing productive training policies and practices in the future for mature-aged workers (Ahl, 2006). Beyond societal factors, participation in training of mature-aged workers is also shaped by complex sets of personal factors, such as readiness for and interest in participation (Billett \& Pavlova, 2005), factors which are often impacted by family and life demands that are particular to this age group. Importantly, these personal factors are perhaps less well understood and need to be informed through qualitative accounts. Yet, as noted, there are few available studies that inform about these factors. In comparison to the large body of quantitative studies that reveal statistical data concerning training programs and mature-aged workers, the body of qualitative studies that explores the personal perspectives of mature-aged workers involved in training programs 
remains quite small. Given the heterogeneous nature of mature-aged workers (Dawe, 2009), and the large age range this classification covers, that being 45-64 years, it would follow that there would be a diversity of personal factors. These personal factors would include the role of individual agency (e.g. intentionality, subjectivity and identity) and the relational interdependence between institutional or social factors and individual agency (Billett, 2006), with relevance to mature-aged workers.

Given that these personal factors of motivations (i.e. intentionality and interest) and experiences of mature-aged workers likely need to be understood and their potency gauged, and these need to be articulated by these workers’ perspectives, a phenomenological approach was considered the most appropriate method. The specific context for the investigation of these motivations and experiences reported here is mature-aged workers' participation in the Certificate IV in Training and Assessment (TAA) qualification. This qualification has been selected because it represents a pertinent and opportune context for inquiry. It is pertinent in the training and development field, because all nationally recognised training in Australia is required to be delivered and assessed by individuals who have successfully completed the Certificate IV in TAA qualification or equivalent competencies (Department of Education, Science and Training [DEST], 2007a). Consequently, this Certificate has an integral role in the delivery of quality training as it defines the competencies (i.e. skills and knowledge) required for the delivery of nationally recognised training in Australia and many workers of this age group are being encouraged to acquire a qualification (Older and Mature Age Workers, 2007), to maintain their employment, enhance their employability (Karmel \& Nguyen, 2007), or at least improve their “labour market attachment” (O’Connell, 2005, p. 21). Some studies suggest that mature-aged workers are interested in making particular contributions through assisting others learn the knowledge they have, such as in a coaching or mentoring role (Billett, 2002, 2010; Lundberg \& Marshallsay, 2007). Hence, gauging factors 
that are pertinent to motivate mature-aged workers' participation in this course can be used as a pertinent context within which to inquire into their motivations to participate in a training program, and identify what combinations of personal and institutional factors may inhibit or assist their participation. This choice was also opportune because of its personal relevance to the first-named author as an adult educator, in her role of delivering the Certificate IV in TAA qualification. As such, she has an informed platform from which to observe and comprehend the bases by which cohorts of these workers engage in these programs.

It is anticipated that the findings derived from an exploratory study may inform stakeholders such as training policy-makers, vocational education and training (VET) program designers and developers and employers how best to motivate and engage matureaged workers in training programs and, thereby, productively participate longer in the workforce.

\section{INVESTIGATING WHAT ENGAGES MATURE-AGED WORKERS IN TRAINING PROGRAMS}

A phenomenological approach was selected for the investigation because of its use of procedures that seek to explore, describe and analyse experiences of a small group of respondents regarding a shared 'phenomena' (Creswell, 2007; Miles \& Huberman, 1994; Smith, Flowers \& Larkin, 2009). This choice was seen as being the most appropriate method because of the identified need to gain insights into personal motivations and interests. As foreshadowed, the extent and scope of current literature from adult and continuing education journals and other publications that explicitly explore personal experiences of mature-aged workers are quite limited. While there are studies that predominantly use qualitative methodologies, such as case studies and interviews, these are dwarfed in number by those using surveys and other quantitative approaches such as those from the ABS. NCVER also uses quantitative methodologies such as surveys to gather statistical data on trends such as the numbers of employers using the VET system. Given that these data reveal a diminishing 
percentage of mature-aged workers participating in training programs, a qualitative methodology with a phenomenological approach was adopted in this study to explore why this is the case from these workers' perspectives, and to understand the reasons behind trends reported in quantitative accounts. These goals are supportive of using small representative studies of between 5-25 participants, (Creswell, 2007), and for this reason, was adopted for the study that is reported and discussed in this article.

The procedures used to gather data comprised open-ended questions in semistructured interviews as this gave access to data that was personal, subjective and insightful regarding motivations and experiences. Interviews were conducted with a small participant group (8) of mature-aged workers enrolled in a Certificate IV in TAA qualification at the time of the interview. The questions in the interview schedule sought to elicit the reasons why these individuals were participating in the Certificate IV qualification, how they were being supported during the course and their experiences while participating.

The common factors of the eight participants were their age, that being 45 years and over, and their participation in the Certificate IV at a registered training organisation (RTO) in 2009. The number of participants was considered ideal for a small representative sample from which to gather in-depth and personal data of the kind required to understand motivations and intentionality (Creswell, 2007). The informants were initially approached through personal contact while they were enrolled in the course and invited to participate in the research. However, this invitation was enacted in a way that secured informed voluntary consent to participate.

The principal research question that guided the focus and conduct of the study was: 'What are the learning needs and factors that motivate and engage mature-aged workers to participate in a training program?' Interview items containing sub-questions that were designed to inform this principal question, included those about: i) age, ii) employment status, 
iii) previous educational history, iv) reasons for participating, v) expectations prior to attending, vi) sources of support, vii) perceptions of mature-aged workers and viii) suggestions for removing barriers to participation.

A phenomenological approach for analysis of the data was also adopted because of the nature of the inquiry, that of an exploration into the shared experience of a phenomena. As a result of a careful and systematic reading of the interview transcripts and identifying patterns of similarity and distinctiveness within them, the data were ordered into five categories. Interpretations, based on these summaries, were made of the participants' experiences within the context of their participation on the training course. A discussion follows, which analyses the main themes, and attempts to define the 'essence' of these experiences.

\section{MATURE-AGED WORKERS: THEIR MOTIVATIONS AND EXPERIENCES}

As noted, the study described in this article had two main focuses of inquiry: the learning needs of mature-aged workers and factors that motivate them to attend training programs. Both of these focuses informed the identification of five sets of themes identified through analyses of interview data. These five themes are now overviewed as sets of findings here with the empirical evidence and justifications elaborated elsewhere (Meyers, 2010).

Firstly, the group of participants, although commonly labelled as mature-aged workers, were quite heterogeneous over a range of measures. It was found that there was little commonality in their demographic backgrounds, life histories, educational achievements and personal motivations for participating in the training program. Even within this small cohort, there was a large age range within the designated group called 'mature-aged workers', that is, they ranged from between 45-64 years, there was a diverse employment status, that is, three were employed, one was unemployed through retrenchment, one was due to be retrenched and there were several part-time employees, and they had diverse educational backgrounds. Even so, workers within this group are treated in a certain way, with one woman, who we 
shall call Heather, applying for financial assistance from Centrelink, describing as “embarrassing" her experience of having to undergo a psychological test to determine her capacity to undertake full-time employment, solely due to her age - that being, over 55 years. This supports the point in the literature review by Billett and van Woerkom (2008), that this cohort cannot be seen to be one homogenous group, and emphasises the diversity of personal backgrounds, histories and other factors that shape participation in work and educational activity. Therefore, a 'one size fits all' approach to a policy or strategy will not meet all of the goals of this cohort, because it would be incapable of meeting such a diverse set of personal needs and hence, motivations.

Secondly, concerning the main theme of motivations or reasons for participating in the Certificate IV in TAA qualification, it was found that within this group of participants, the primary motivation for attending was for regulatory purposes (i.e. to be permitted to train and assess others in accredited training programs). That is, motivation was from an external pressure or institutional factor, and was not internally driven by personal motivations or interest. This external motivation provided a stimulus to attend, but did not necessarily produce enthusiastic course participants (i.e. engaged learners). Rather, in some cases, it generated a reluctance to participate, in particular, with a woman we shall call Jane, who described her having to undergo further training as "the lesser of two evils", in that she could either become a trainer, or a marketing officer, if she wanted to remain in her employment. These sorts of sentiments had implications for their engagement in and, therefore, successful completion of this course. However, the extent and purchase of the external drivers to participate were distinct across this small cohort. Moreover, and importantly, it was also found that these participants had diverse personal bases for deciding to acquire a qualification to become trainers and assessors of accredited training at this time in their working lives. In this way, participation in this program was premised on both 
institutional factors in the form of regulatory arrangements, and individual personal factors. Yet, the combinations and interdependencies that comprised these sets of factors for each of this small cohort were quite diverse. That is, the interplay between institutional and personal factors was playing out in personally-distinct ways.

Thirdly, the data revealed that prior to attending the course, the participants had many personal characteristics that impacted on their engagement in the course and which were influenced by their previous experiences in education and workplace training. Quite a few participants commented that they felt "out of their comfort zones" or "totally out of my league" when participating in the course. In turn, these factors influenced their readiness or ability to engage fully with the learning. These characteristics included: i) lack of computer literacy, with one woman commenting she was a "computer dodo", ii) personal anxieties, with one woman commenting she was "daunted and overwhelmed at first", and iii) varying needs for financial support from employers or government agencies, such as the experience of 'Heather'. This list highlights the range and diversity of the personal needs of mature-aged workers that manifested itself as quite distinct kinds of readiness to participate in this program. Several participants reported having personal anxieties from prior and much earlier experiences in educational programs, which they claimed influenced much of how they engaged in this particular learning experience. In terms of completing assessment tasks, it was found that those who had little or no previous experience of accredited training and had low computer literacy skills reported completing the tasks was “confusing” and "frustrating”. In contrast, those with previous experience of accredited training and high computer literacy found few difficulties completing them. Hence, their readiness to participate in the program was quite diverse.

Fourthly, the theme of provision of support (i.e. an institutional factor) revealed that for this group, although this qualification is a regulatory requirement for training and 
assessing accredited training, employers and government bodies did not automatically or sufficiently support them in securing it. Of the eight participants, only three had their course fee paid for by their employer, with five paying their own course fee in order to secure future employment or maintain their current employment. One participant stated the course fee was "very expensive" and that she wouldn't have done it had her employer not paid. It was also found that although government bodies, such as Centrelink (a state-sponsored employment agency), purported to encourage mature-aged workers to attend training courses, one participant's experience was that financial support from this source was not provided. These experiences indicate the differential ways in which institutional arrangements were afforded to this small cohort of mature-aged workers.

Finally, it was found that among this group, perceptions of their cohort's ability to be productive and capable workers differed and these perceptions were often related to their industry. For example, in a certain industry, to which one participant, who we shall call Glenda, had been affiliated for years, stated that mature-aged women "had a lot to offer" and were "reliable and compassionate", thus were highly regarded and indeed, sought after. However, a woman we shall call Jane, stated her age cohort were "over-qualified and over-experienced for the pay we receive”. One male, whom we shall call Charles, was strong in his condemnation of the treatment of his cohort, stating he felt they were "severely disadvantaged, almost criminally" in the workforce and discriminated against in the community: an institutional factor. There was also a perception shared among several in this group of participants that mature-aged workers, particularly women, did not value themselves, or have confidence in their own abilities, and this impacted on their decisions to access training programs. Participants inevitably suggested a variety of strategies for removing barriers to their cohort participating in training programs, such as forming community support networks. 
In summary, this set of five findings illuminate how personal and institutional factors both singly and relationally, serve to explain the bases for these individuals' participation in training programs. As such, they provide some indications of the range of factors that need to be negotiated individually to understand how measures to improve mature-aged workers' participation in training programs might be realised. Fundamentally, these measures would need to account for the personally-negotiated institutional and personal factors. That is, measures relying on institutional imperatives and ignoring personal imperatives, and vice versa, will likely be unsuccessful.

The following table shows the range of factors that were identified as influencing mature-aged workers' participation in the training program and lists whether they are construed as being institutional or personal factors. The factors are listed on the left-hand side of the table, under either institutional or personal, and descriptions of each of the factors are listed on the right-hand side. All of these factors are interdependent, that is, there are relational interactions between these factors that need to be negotiated by the individual. The degree to which an individual successfully negotiates between these factors depends on the level of motivation and engagement they have towards the desired outcome.

Table 1. Factors influencing mature-aged workers' participation in training programs

\begin{tabular}{ll}
\hline Factors & Descriptions \\
\hline Institutional & \\
\hline Demographic trends & Ageing population, decreasing fertility rates, skills obsolescence \\
\hline Societal sentiments & $\begin{array}{l}\text { Ageism, belief in declining cognitive and training capabilities of } \\
\text { mature-aged workers }\end{array}$ \\
\hline Workplace affordances & $\begin{array}{l}\text { Inequitable opportunities as employees age, less offering of } \\
\text { employer-sponsored workplace learning }\end{array}$ \\
\hline Regulatory requirements & $\begin{array}{l}\text { Industry-regulated requirements to gain qualifications prior to } \\
\text { employment or to continue in employment }\end{array}$ \\
\hline Personal & \\
\hline Personal histories & Social and cultural background, dispositions, epistemologies \\
\hline
\end{tabular}




\begin{tabular}{ll}
\hline Learning and work history & $\begin{array}{l}\text { Pre-mediate learning and work experiences, qualifications, training, } \\
\text { current and relevant skills }\end{array}$ \\
\hline Expectations & Based on previous experiences and personal histories \\
\hline Levels of support & $\begin{array}{l}\text { Financial, emotional, social, physical and learning needs, impacted by } \\
\text { institutional factors }\end{array}$ \\
\hline Readiness & $\begin{array}{l}\text { Level of preparedness to participate in training programs (i.e. } \\
\text { capacities to effectively engage with selected training approach) }\end{array}$ \\
\hline
\end{tabular}

What is advanced by Table 1 is that there are a range of personal and societal factors that shaped mature-aged workers' participation in training programs. On the one hand, there is the need for mechanisms that overcome societal constraints, yet afford access to and support in these programs. On the other, are sets of personal factors that will be individually distinct to a degree. Yet, more than two sets of factors, there are also relations amongst them that suggests something of the complexity of the premises under which participation in training programs proceed. Whilst there can be no expectation that personally tailored programs will be available or realisable, what the findings here suggest is that initiative premised on government and employer imperatives alone will be insufficient. Instead, there is a need to understand the motivations to access and bases by which mature-aged workers will engage in these programs.

\section{MATURE-AGED WORKERS AND TRAINING PROGRAMS IN PROSPECT}

As noted above, the purpose of this study was an initial exploration of the learning needs and factors that motivated and engaged a small cohort of mature-aged workers to participate in an accredited training program. Due to the scale of this study, there can be no broadly applicable conclusions extended from these findings. However, from the interpretations of the summaries of the main themes, some implications can be drawn and suggestions for future strategies and studies can be recommended.

The diversity of ages, educational background and employment status within the age definition of 'mature-aged workers' in this study indicates the likely shortcomings of creating one single policy or strategy to address the learning needs of all mature-aged workers. This 
conclusion suggests that breaking down the age range into a series of smaller age groups may be advisable and helpful in aligning support with the specific needs of different age groups, but that measure alone will be insufficient. While the needs of those in the older age range is one of particular concern (O’Connell, 2005; Dawe, 2009), with the difficulties of attempting to gain employment after retrenchment impacting heavily on these workers in terms of their sense of selves and ability and willingness to access formal training programs, future studies might focus on this particular age group and the issues peculiar to them. There are likely to be greater complexities for those who are unemployed or facing retrenchment than those matureaged workers who are in employment. Indeed, it would be easy to dismiss the findings here as pertaining to all participants in training regardless of age. This is in some ways true. However, for these workers the time since leaving school, the legacies of recent experiences, the pace of change and the perils of failure may be more extreme, and perhaps more so for those who are unemployed.

Further, the institutional factor of sources of support seems a crucial one, impacting on personal factors such as learning needs, experiences, expectations and motivations. A common theme advanced by participants was that of the ignorance of employers, industries and government bodies (such as job-finding agencies, e.g. Centrelink) of the support needed by mature-aged workers, firstly, in accessing relevant training programs, which often requires financial support, then while undertaking an accredited training qualification, such as the Certificate IV in TAA, which places considerable demands on their time. However, it appears there is an increasing disparity between the rhetoric and, to some extent, the policies of the Federal Government (DEEWR) and their actual practices regarding the issue of increasing the labour force participation rate of mature-aged workers through workplace training or accredited training programs. It is suggested that the government address this disparity to determine where policy and practice can be more effectively aligned. In addition, there needs 
to be a shift in the attitudes of the community regarding the valuing of this age cohort's experience, knowledge and reliability. This is not only with respect to the younger members of the community; mature-aged workers need to learn to value themselves, and, in particular, their "wisdom”, as one participant phrased it. Therefore, future policy changes should focus on promoting the critical importance of both accredited training and mature-aged workers in meeting national goals. In this way, an institutional factor, such as government policy, can support and enhance the individual personal factors of these workers, even though they are idiosyncratic and diverse. For mature-aged workers to be encouraged to participate in training, they need to believe they are worthy of training, in terms of a financial and time investment. Policies which uphold the intrinsic value of this age cohort and mandate equal workplace opportunities would allow for personal factors to be taken into consideration and supported, rather then their being a hindrance to individual decision-making regarding participation in training programs. So, it can be seen that, personal factors may be individual, but they exist and have an inter-relational interdependence within a social world, that is, one constituting institutional or societal factors. It will be the successful negotiation between these two intertwining factors that determines the success or otherwise of the national goals of encouraging larger numbers of mature-aged workers to remain longer in or re-join the labourforce.

Finally, it was found that participating members of this age group are extremely willing and able to articulately describe their personal experiences. In exploring their needs and motivations through descriptions of personal experiences, it was found there was no shortage of data available, due to a generous willingness of the participants to 'share'. Yet, across this small cohort just something of the rich interplay between institutional and personal factors played out. There is much more to be learnt about. For instance, these workers were relatively highly educated, and better placed than many other mature-aged Australian 
workers. Therefore, future studies are required that can explore more comprehensively the factors which shape the decisions of mature-aged workers to engage in training programs, and there may be many willing participants, once there is an appropriate forum and opportunity to voice their concerns. It would greatly benefit the national goals if the government, employment and training sectors were to listen to mature-aged workers’ stories. 


\section{REFERENCES}

Ahl, H 2006, Motivation in Adult Education: A problem solver or a euphemism for direction and control? International Journal of Lifelong Learning, vol 25, no.4, pp385-405.

Australian Bureau of Statistics 2009, Mature-aged Workers: Sustaining Our Future Labour Force. Report, Canberra, ACT.

Australian Human Rights Commission 2009, Experience Works Report highlights our hidden age discrimination problem, Media Release, 30 July, 2009.

Barton, T 2005, Valuing Older Workers: Preparing your business for an ageing workforce, Report to State of Queensland Department of Industrial Relations, Brisbane, QLD.

Billett, S R 2002, Toward a workplace pedagogy: Guidance, participation and engagement, Adult Education Quarterly, vol 53, no.1, pp27-44.

Billett, S R \& Pavlova, M 2005, Learning through working life: self and individuals’ agentic action, International Journal of Lifelong Education, vol 24, no.3, pp195-211.

Billett, S R 2006, Relational interdependence between social and individual agency in work and working life, Mind, Culture and Activity, vol 13, no.1, pp53-69.

Billett, S R \& van Woerkom, M 2008, Personal epistemologies and older workers, International Journal of Lifelong Learning, vol 27, no.3, pp333-348.

Creswell, J W 2007, Qualitative Inquiry \& Research Design: Choosing Among Five Approaches ( $2^{\text {nd }}$ Edition), Thousand Oaks, CA, USA: Sage Publications.

Dawe, S 2009, Older Workers \& VET: at a glance. National Centre for Vocational Education Research Report, Adelaide, SA.

Department of Employment, Education and Workplace Relations 2008, Australian vocational, education and training statistics: Employer use and views of the VET system, 2007 Summary, National Centre for Vocational Education Research, Adelaide, South Australia. 
Department of Education, Science and Training 2007a, AQTF 2007: Essential Standards for Registration, Department of Science, Education and Training, Canberra, ACT.

Dimopoulos, N 2005, Lifelong Learning/CEDA. Committee for the Economic Development of Australia (CEDA), Growth, Number 56.

Encel, S 2003, Age Can Work: The case for older Australians staying in the workforce, A report to the Australian Council of Trade Unions and the Business Council of Australia, University of New South Wales.

Hancock, L 2006, Mature Age Workers, Training and Using TLM Frameworks, Australian Bulletin of Labour, 2006, vol 32, no.3.

Karmel, T \& Nguyen, N 2007, The value of completing a VET qualification, National Centre for Vocational Education Research Report, Adelaide, SA.

Kossen, C 2004, Rethinking the value of older workers: a resource growing in importance, Business research papers, vol 11, no.1, 2004.

Linacre, S 2007, Australian Bureau of Statistics - Annual Report, 2006-07, Commonwealth Government, Canberra.

Lundberg, D \& Marshallsay, Z 2007, Older workers’ perspectives on training and retention of older workers: support document - South Australian construction industry study, National Centre for Vocational Education Research Report, Adelaide, SA.

McFarlane, J 2004, Ageing and Productivity: What can we do? Australian Chief Executive, April 2004, pp26-29.

Meyers, R 2010, Investigating the learning needs and factors that motivate and engage mature-aged workers to participate in training programs, Master of Education thesis.

Miles, M B \& Huberman, A M 1994, Qualitative Data Analysis (2 ${ }^{\text {nd }}$ Edition), Thousand Oaks, CA, USA: Sage Publications.

O’Connell, M 2005, The role of training in preventing the labour market exclusion of older 
workers, Refereed paper presented to the Transitions and Risk: New Directions in Social Policy Conference. University of Melbourne, VIC.

Organisation for Economic Co-operation and Development (OECD) 2010, Country memo as a background paper for the OECD Disability Review, November 2007, The OECD “Sickness, Disability and Work” project, from the website www.oecd.org/els/disability accessed September, 2010.

Older and Mature Age Workers 2007, from the website www.olderworkers.com.au accessed October, 2008.

Productivity Commission 2005, Economic Implications of an Ageing Australia, Research Report, Canberra, ACT.

Rolland, L 2004, Age management: responding to an older workforce, Australian Chief Executive, April 2004, pp30-32.

Searle, J R 1995, The construction of social reality, London, Penguin.

Smith, A \& Billett, S R 2005, Myth and Reality: Employer sponsored training in Australia International Journal of Training Research, vol 3, no.2, pp16-29.

Smith, J. A., Flowers, P \& Larkin, M 2009, Interpretative Phenomenological Analysis, London, UK: Sage Publications.

The Treasury 2004, Australia's demographic challenges, Canberra: The Treasury - Social policy division. 